\title{
'Desperate larvae' revisited: age, energy and experience affect sensitivity to settlement cues in larvae of the gastropod Alderia sp.
}

\author{
Gilberto Botello, Patrick J. Krug* \\ Department of Biological Sciences, California State University, 5151 State University Drive, Los Angeles, \\ California 90032-8201, USA
}

\begin{abstract}
Formulated in the 1950s, the 'desperate larva' hypothesis postulated that lecithotrophic larvae become less discriminating in their settlement requirements over time, due to depletion of energy reserves. Its predictions have been confirmed for some taxa in which larvae settle gregariously or in response to biofilms, but the hypothesis has not been tested with larvae that exhibit a stringent requirement for prey- or host-derived settlement cues. Using the opisthobranch Alderia sp., we tested how age, nutritional status and prior experience affected larval response to settlement cues from the host alga Vaucheria longicaulis. Although able to metamorphose without feeding, larvae of Alderia sp. were facultatively planktotrophic if phytoplankton were available, allowing us to test the effects of energy limitation on dose-response. Unfed larvae became increasingly responsive to dissolved settlement cues with age, whereas the sensitivity of fed larvae did not change over time; larvae thus responded more strongly to habitat cues as energy reserves diminished. Rate of metamorphosis also accelerated with age; following initial settlement, 4 d old larvae completed metamorphosis 12 to $24 \mathrm{~h}$ faster than $1 \mathrm{~d}$ old larvae. Larvae may settle and then continue to evaluate their environment via perception of chemical cues, with older larvae initiating metamorphosis more rapidly. Prior exposure to a subthreshold dose of the natural cue triggered a higher response to a subsequent exposure in initial non-responders. Some families exhibited a lower threshold dose than others, suggesting that cue sensitivity may have a heritable component. Habitat choice thus depends on interactions between the genetic background, prior experience and energy content of a given larva. Our results support a modified version of the original desperate-larva hypothesis applicable to nongregarious species, in which energy-depleted larvae accept weaker cues and respond more quickly during habitat selection.
\end{abstract}

KEY WORDS: Lecithotrophy $\cdot$ Facultative planktotrophy $\cdot$ Settlement $\cdot$ Metamorphosis $\cdot$ Alderia sp. Opisthobranch $\cdot$ Desperate larva hypothesis $\cdot$ Dose-response

\section{INTRODUCTION}

For sessile, slow-moving or territorial marine organisms, dispersal and habitat choice are largely the province of planktonic larvae (Pechenik 1999). The dispersal potential of lecithotrophic (non-feeding) larval stages is energetically constrained by endogenous reserves, unless offset by uptake of dissolved organic matter (Jaeckle \& Manahan 1989, Shilling et al. 1996). Most lecithotrophic larvae therefore have limited time to locate and colonize a suitable adult habitat. Dominant spatial competitors such as barnacles and tubebuilding polychaetes often settle gregariously, metamorphosing on conspecific adults to create aggregations (Knight-Jones \& Stevenson 1950, Knight-Jones 1951, 1953a, Pawlik 1992). About 50 yr ago, it was noted that non-feeding polychaete larvae became less dependent on settlement cues with age (Knight-Jones 1953b, reviewed in Toonen \& Pawlik 2001a). It was proposed that as larvae depleted their available 
energy reserves, they became 'desperate' to settle, and would accept a suboptimal site rather than risk death before metamorphosis. The desperate larva hypothesis (DLH) accounted for laboratory results with non-feeding larvae, and also explained how bare patches are initially colonized in the field.

The DLH proposes that habitat selectivity is subject to energetic constraints in non-feeding larvae (KnightJones 1953b, Toonen \& Pawlik 2001a, Marshall \& Keough 2003). Delay of metamorphosis increases the risk of larval mortality, and can incur post-metamorphic costs (Woollacott et al. 1989, Pechenik 1990, Qian \& Pechenik 1998, Wendt 1998, Maldonado \& Young 1999, Pechenik et al. 2002, Marshall et al. 2003b). However, choosing a poor habitat is also likely to have severe fitness consequences for an organism. The DHL predicts that when the costs of delaying metamorphosis exceed those of choosing an inferior habitat, selection will favor larvae that metamorphose rather than extend their planktonic period. Data supporting the DLH have come largely from studies of sessile, filterfeeding taxa such as polychaetes, bryozoans and ascidians (Knight-Jones 1953b, Wendt 1998, Marshall $\&$ Keough 2003). Presence of adults may indicate suitable abiotic (e.g. tidal height) and biotic (e.g. absence of predators) conditions but, in principle, any hard substratum offers such species an attachment site and the opportunity to feed. A juvenile isolated on a bare rock can filter-feed in the absence of conspecifics, and if it survives long enough for other larvae to settle on it or nearby, may obtain access to mates. The increasing acceptance of biofilmed surfaces by aging larvae can thus be viewed as an adaptive response to the diminishing returns of a continued planktonic existence once energy reserves decline below a threshold level.

Other organisms produce larvae that metamorphose only in the presence of an obligate host or prey species. For example, larvae of the sacoglossan sea slug Alderia sp. metamorphose in response to dissolved and surface-bound chemical cues produced by the host alga Vaucheria longicaulis, the sole food of juveniles and adults (Krug \& Manzi 1999, Krug \& Zimmer 2000a, Krug 2001). This species, previously considered a regional variant of its exclusively planktotrophic congener A. modesta, is presently being described from southern and central California where it produces both lecithotrophic and planktotrophic larvae (Krug 1998, P. J. Krug \& R. A. Ellingson unpubl. data). As originally formulated, the DLH should not apply to a host-dependent species; if larvae metamorphose non-specifically, juveniles will be unable to feed in the absence of their host, and will not survive to reproduce. Lecithotrophic larvae of such trophic specialists have the same energetic constraints as non-feeding larvae of filterfeeders, however, suggesting they may have analo- gous adaptations to offset the costs of a prolonged planktonic period. Some specialist larvae can complete metamorphosis without feeding, but are capable of facultative planktotrophy when food is available (Kempf \& Hadfield 1985, Kempf \& Todd 1989, Miller 1993). Facultative feeding can offset post-metamorphic fitness consequences of an extended larval life, but how it affects patterns of habitat choice remains unexplored.

In the classic formulation of the DLH, larvae choose between optimal versus available habitat, over time becoming increasingly apt to settle on a biofilmed substratum. Lecithotrophic larvae of Alderia sp. do not fit this model, remaining dependent on cues from the host alga for metamorphosis as they age (Krug 2001). Alternatively, larvae could remain host-specific, but respond to weaker cues of habitat suitability over time. This formulation of the DLH incorporates the phenomenon of dose response, instead of focusing on the presence or absence of a particular cue. Larvae that respond to dissolved cues initiate metamorphosis at a concentration exceeding some threshold set by the larval nervous system, with fewer larvae metamorphosing when the cue is more dilute (Tamburri et al. 1992, Krug \& Zimmer 2000a,b). With age, larvae may accept a lower dose as an indicator of an acceptable habitat. Alternatively, older larvae could initiate metamorphosis more rapidly after encountering their host, whereas younger larvae can energetically afford to delay the onset of metamorphosis while evaluating their surroundings; in addition to decreased substratespecificity, increased rates of settling have been reported for older polychaete larvae (Knight-Jones 1953b, Pechenik \& Cerulli 1991). We therefore investigated whether the DLH applied to a non-gregarious species with a strict settlement-cue requirement, testing the effects of age, nutritional status and prior experience on the response threshold and rate of met morphosis in larvae of the coevolved habitat specialist Alderia sp.

\section{MATERIALS AND METHODS}

Study organism. Specimens of Alderia sp. and patches of Vaucheria longicaulis were collected from the Kendall-Frost Northern Wildlife Preserve (San Diego, California; $\left.32^{\circ} 47^{\prime} 36^{\prime \prime} \mathrm{N}, 117^{\circ} 13^{\prime} 47^{\prime \prime} \mathrm{W}\right)$, the Upper Newport Bay Ecological Reserve (Newport, California; $33^{\circ} 37^{\prime} 16^{\prime \prime} \mathrm{N}, 117^{\circ} 53^{\prime} 32^{\prime \prime} \mathrm{W}$ ) and a manmade wetland adjacent to the Los Angeles Harbor (San Pedro, California; $33^{\circ} 42^{\prime} 48^{\prime \prime}$ N, $\left.118^{\circ} 17^{\prime} 02^{\prime \prime} \mathrm{W}\right)$. Seawater from Scripps Institution of Oceanography (La Jolla, California) was filtered to $0.22 \mu \mathrm{m}$ (FSW) prior to use. Adult slugs were held in shallow dishes of seawa- 
ter overnight for egg-mass deposition. For batch cultures of larvae, >100 egg masses were pooled and maintained in FSW, which was changed every other day until hatching. Egg masses of Alderia sp. contain $32 \pm 12$ larvae of the larger size morph, and hatch synchronously (Krug 1998). As only larvae hatching on the morning of the 6th day post-deposition of egg masses were used in cultures and experiments, all larvae within a given batch were within $\sim 4$ h of age. Larval settlement and metamorphosis can be induced by either waterborne compounds from, or contact with, tissue of the host alga $V$. longicaulis (Krug 2001, Krug \& Zimmer 2000a). In Alderia sp., larval settlement is a firm but reversible attachment to a substratum by the foot; settled larvae cannot be easily dislodged by a jet of water from a pipette. Metamorphosis is the irreversible transformation into a juvenile, which can immediately feed on $V$. longicaulis.

Solutions of dissolved settlement cue. Stock solutions of the waterborne cue were prepared using Vaucheria longicaulis collected from San Diego or Newport Bay as described by Krug \& Manzi (1999). Algal tissue (1.34 $\mathrm{g}$ wet weight) was boiled in distilled water $(50 \mathrm{ml})$ for $10 \mathrm{~min}$ and the resulting boiled $V$. longicaulis extract (BVE) was centrifuged to clarity. A mixture of high- and low-molecular weight carbohydrates in BVE induces settlement behavior and metamorphosis (Krug \& Manzi 1999, Krug \& Zimmer 2000a). The BVE stock was diluted with FSW and used in dose-response experiments; dose is expressed as a percentage of undiluted extract. The $\mathrm{EC}_{50}$ (dose of half maximal biological effect) for extracts ranged from 0.25 to $0.5 \%$, consistent with prior results (Krug \& Zimmer 2000a).

Genetic variance in dose-response threshold. A single large egg mass was isolated from each of 10 different adults. Given the sperm storage abilities of Alderia sp., clutch-mates may be either full or half siblings (Angeloni 2003). All parent slugs were collected at the same time and site, but maternal condition was not otherwise assessed. Upon hatching, larvae from each clutch were divided into replicate dishes $(n=3$ to 6 per clutch), each containing 15 larvae and a $0.4 \%$ solution of BVE. Percentages of metamorphosis were arcsine square-root-transformed, and between-family versus within-family variance was compared using a 1-way ANOVA with a Student-Newman-Keuls test for unplanned comparisons.

Effect of age on sensitivity to dissolved cues. To test whether unfed larvae became increasingly sensitive to dissolved cues with age, we generated dose-response curves for larvae subsampled from batch cultures at different times. For each experiment, egg masses were hatched together and the resulting pool of larvae maintained in $1 \mathrm{l}$ of FSW at 1 larva $\mathrm{ml}^{-1}$. Subsamples of larvae were drawn after 1, 3, and 5 d post-hatching, and exposed to 4 concentrations of BVE ranging from 0 to $1 \%$ ( $\mathrm{n}=4$ replicate dishes per dose); extract was prepared from Vaucheria longicaulis collected at Newport Bay. The experiment was repeated 3 times on independent batches of larvae from separate collections of adult slugs from San Pedro, California (December 2003 and March and April 2004). Percentages of metamorphosed larvae were scored after $48 \mathrm{~h}$ and normalized using an arcsine square-root-transformation (Sokal \& Rohlf 1995); doses were linearized by a $\log ($ dose +1$)$ transformation. Many $5 \mathrm{~d}$ old larvae died during the assays, so only results from 1 and 3 d old larvae were compared. Multiple linear regression (implemented in Statview software) was used to model the relationship between transformed percent metamorphosis, logtransformed dose, larval age, and batch as a dummy variable, with backward elimination of variables that were not significant predictors.

Effect of nutritional status versus age on sensitivity to dissolved cues. A single adult of Alderia sp. can toggle between production of planktotrophic and lecithotrophic larvae. Given this developmental flexibility, we hypothesized that 'lecithotrophic' larvae might retain the ciliary bands and enzymes needed to capture and digest phytoplankton, like other opisthobranch larvae that are facultatively planktotrophic (Kempf \& Todd 1989, Miller 1993). To test this, larvae were incubated overnight in a 1:1:1 suspension of the phytoplankton Rhodomonas sp., Isochrysis galbana, and Pavlova lutheri at a concentration of $\sim 10^{4}$ cells ml ${ }^{-1}$, and their gut contents examined by light microscopy for pigmented algal cells on the following day.

To determine if sensitivity to dissolved cues increased due to age itself or depletion of energy reserves, we then compared the dose-response of fed versus unfed larvae 1, 3, and $5 \mathrm{~d}$ post-hatching (August 2004). A collection of $>100$ egg masses laid by adults from San Pedro was randomly divided into 2 subcultures; one culture was maintained in FSW, while the other was hatched in a suspension of phytoplankton as above. Larvae were maintained at $22^{\circ} \mathrm{C}$ under ambient light at 1 larva $\mathrm{ml}^{-1}$; cultures were agitated daily but were otherwise static. Every other day, larvae were sieved through a $52 \mu \mathrm{m}$ mesh and transferred to clean FSW with fresh phytoplankton. Subsampled larvae of each age and treatment were used to generate a doseresponse curve as before (4 replicate dishes per dose, 15 larvae per dish). Percentages of metamorphosis and doses were transformed as before, and analyzed by multiple regression testing of (1) age, (2) dose and (3) fed versus unfed treatment as a dichotomous variable, with 'unfed' status coded as 0 and 'fed' as 1 .

Effect of prior exposure to a subthreshold dose on subsequent response to dissolved cues. Larvae that 
Table 1. Alderia sp. Experimental design testing effects of prior exposure to subthreshold dose of dissolved settlement cue on subsequent larval metamorphosis, whereby $1 \mathrm{~d}$ old larvae ( $\mathrm{n}=4$ replicates per treatment) were exposed to an initial dose (filtered seawater [FSW] or $0.2 \%$ boiled Vaucheria longicaulis extract [BVE]) for $48 \mathrm{~h}$; those larvae not undergoing metamorphosis were then transferred to clean FSW for a further $24 \mathrm{~h}$, after which remaining veligers were exposed to a second dose (FSW or $0.2 \%$ BVE) for a final $48 \mathrm{~h}$. Final percentages of metamorphosis were thus determined for larvae that were $3 \mathrm{~d}$ old at the beginning of the second dose

\begin{tabular}{|lccc|}
\hline Treatment & $\begin{array}{c}\text { 1st dose } \\
(\text { Days 1+2) }\end{array}$ & $\begin{array}{c}\text { Wash } \\
(\text { Day 3) }\end{array}$ & $\begin{array}{c}\text { 2nd dose } \\
(\text { Days 4+5) }\end{array}$ \\
\hline A & $0.2 \%$ BVE & FSW & $0.2 \%$ BVE \\
B & $0.2 \%$ BVE & FSW & FSW \\
C & FSW & FSW & $0.2 \%$ BVE \\
D & FSW & FSW & FSW \\
\hline
\end{tabular}

fail to metamorphose after exposure to a given dose of BVE may have a higher response threshold. To test the effect of prior exposure to a subthreshold dose, a batch culture was divided into 4 parallel treatments, with 4 replicates per treatment (Table 1). Each replicate had 25 to 50 larvae per dish to start the experiment. For the first $2 \mathrm{~d}$ post-hatching, larvae in Treatments A and B were initially exposed to a dose of $0.2 \%$ BVE, while C and D were kept in FSW. All assays were then scored, and non-metamorphosed veligers were transferred to clean FSW for a daylong 'wash' step. After washing, veligers that were still non-metamorphosed were transferred into new dishes containing either $0.2 \%$ BVE or FSW for a further $2 \mathrm{~d}$, after which assays in all treatments were scored. The entire experiment was replicated with 2 independent batches of larvae from adults collected in San Diego (August 2003 and May 2004). Percentages of metamorphosis were arcsine square-root-transformed and compared by 2-way ANOVA, using batch and treatment as factors; unplanned comparison of means used a post-hoc Scheffé test.

Effect of age on rates of settlement and metamorphosis. Larvae of different ages were used to test the hypothesis that older larvae initiate metamorphosis more quickly upon exposure to the host alga. Larvae were used 1, 2, or $4 \mathrm{~d}$ after hatching. For each age, 15 larvae were added to replicate dishes $(\mathrm{n}=6)$ and incubated with live filaments of Vaucheria longicaulis. Larvae were scored for settlement and metamorphosis $2 \mathrm{~h}$ after algae were added, and at $12 \mathrm{~h}$ intervals thereafter. Percent metamorphosis data did not meet the assumptions of parametric statistics, and were thus compared after 24 and $48 \mathrm{~h}$ within each age class using a Wilcoxon signed-rank test, to determine whether metamorphosis primarily occurred in the first or second $24 \mathrm{~h}$ of exposure to $V$. longicaulis.
Competence assessment prior to hatching. Results showing changes in larval sensitivity over time could be an artifact if not all larvae of Alderia sp. are competent immediately upon hatching. Clutches were therefore incubated with a live piece of Vaucheria longicaulis beginning on the 4 th day after egg deposition, when embryos (i.e. any stage still confined within an egg capsule: Chia 1974) were similar in shell size and morphology to hatched larvae. Embryos ( $\mathrm{n}=4$ clutches) were thus exposed to dissolved cues from the algae for $2 \mathrm{~d}$ prior to hatching, which occurred on the 6th day after deposition in both treatments and controls. Control egg masses $(n=4)$ were held in FSW for the duration of the experiment. Assays were initially scored on the morning of the 6th day, and 12 and $24 \mathrm{~h}$ thereafter. Larvae were scored for both settlement and metamorphosis; settlement was detectable even within the egg mass by the distinctive crawling behavior of settled larvae. Percentages of metamorphosis were compared at hatching and $12 \mathrm{~h}$ after hatching using a Mann-Whitney $U$-test.

\section{RESULTS}

\section{Genetic basis for dose response}

There was significantly more between-family than within-family variation in response to a low dose of the dissolved settlement cue (Fig. 1, and results of a 1-way ANOVA: $\left.F_{9,37}=4.5, \mathrm{p}=0.0005\right)$. Although suggestive of a heritable basis for cue-sensitivity in larvae of Alderia sp., our results were for full or half siblings, and

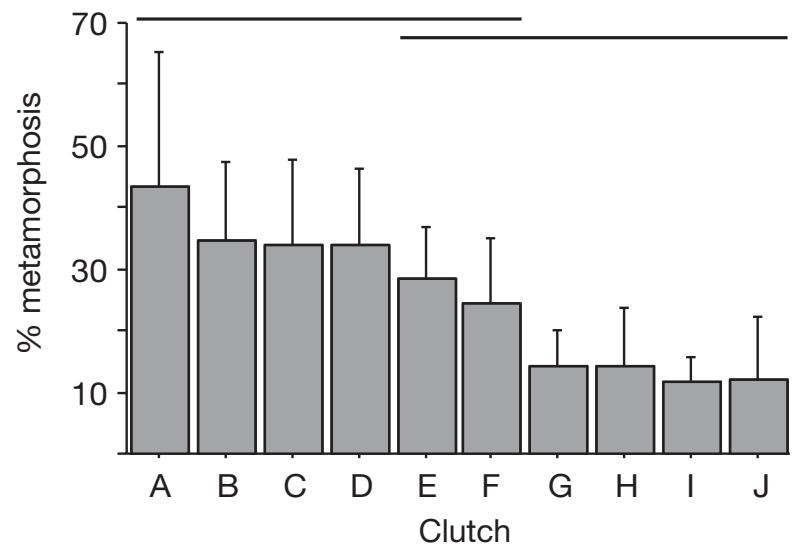

Fig. 1. Alderia sp. Differences in dose sensitivity between larvae produced by different adults. Data are mean (+1 SD) percentages of metamorphosis for unfed competent larvae from 10 clutches in response to dissolved cues from the host alga. Means not joined by a horizontal bar differed significantly (1-way ANOVA followed by post-hoc Student-Newman-Keuls test, $\mathrm{p}<0.05)$. Due to sperm-storage ability of Alderia sp., clutch-mates may be full or half siblings 
given the possibility of maternal effects, estimates of additive genetic variation were not made.

\section{Effect of larval age on dose response}

Larvae were dose-responsive to the dissolved algal cue as expected, but 3 d old larvae were more responsive than $1 \mathrm{~d}$ old larvae in 3 independent trials (Fig. 2). A multiple linear regression yielded a significant model (Table 2; $F_{2,117}=201.53, \mathrm{p}<0.0001$, adjusted $\left.R^{2}=0.771\right)$. Batch was not a significant predictor and was eliminated from the final model. The positive regression coefficients indicate that percent metamorphosis increased with both increasing dose and age;

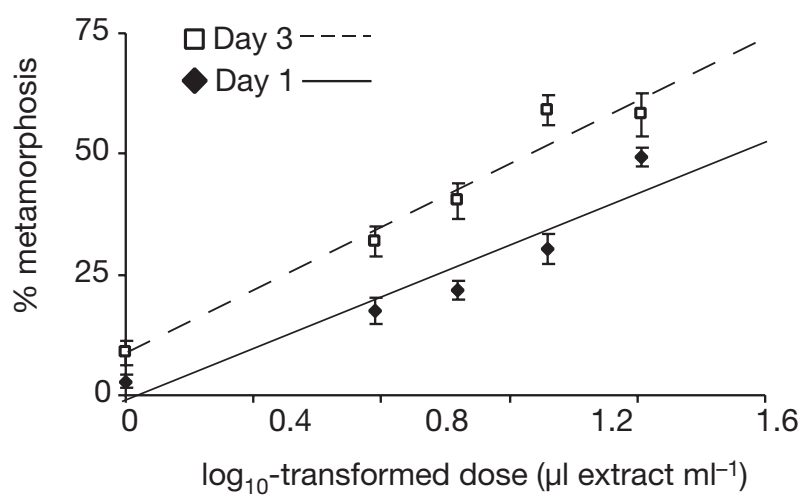

Fig. 2. Alderia sp. Age effects on dose response of larvae. Data are mean $( \pm 1 \mathrm{SE})$ percentages of metamorphosis among larvae hatched and maintained in filtered seawater, and tested 1 and $3 \mathrm{~d}$ post-hatching $(\mathrm{n}=4$ replicates per dose of boiled Vaucheria longicaulis extract [BVE], for each of 3 batches). Data were pooled from 3 independent runs of the experiment, as batch was not a significant predictor of variance

Table 2. Alderia sp. Results of multiple linear regression for effects of log-transformed dose of boiled Vaucheria longicaulis extract (BVE), larval age and batch on percent metamorphosis. Backward elimination was used to remove batch as a variable, as it was not a significant predictor

\begin{tabular}{|c|c|c|c|c|c|}
\hline \multicolumn{6}{|c|}{ Multiple linear regression model } \\
\hline Variable & Coefficient & SE & \multicolumn{2}{|r|}{$t$-value } & $\mathrm{p}$ \\
\hline Intercept & -0.01 & 0.03 & \multicolumn{2}{|r|}{-0.27} & 0.79 \\
\hline Log(dose) & 0.41 & 0.02 & \multicolumn{2}{|r|}{18.59} & $<0.0001$ \\
\hline Age & 0.09 & 0.01 & \multicolumn{2}{|r|}{7.58} & $<0.0001$ \\
\hline \multicolumn{2}{|c|}{ RMS residual = 0.132} & $=0.7$ & & \multicolumn{2}{|c|}{ adjusted $\mathrm{R}^{2}=0.771$} \\
\hline \multicolumn{6}{|c|}{ Analysis of variance } \\
\hline Source of ve & riation df & SS & MS & $F_{\mathrm{s}}$ & $\mathrm{p}$ \\
\hline Regression & 2 & 7.07 & 3.53 & 201.53 & $<0.0001$ \\
\hline Error & 117 & 2.05 & 0.02 & & \\
\hline Total & 119 & 9.12 & & & \\
\hline
\end{tabular}

age contributed about $25 \%$ as much variance as did increasing dose. There was no significant increase in percent metamorphosis in seawater controls between 1 and $3 \mathrm{~d}$ post-hatching; thus, the observed increase in response did not result from more spontaneous metamorphosis among older larvae.

\section{Facultative planktotrophy: effect of larval nutritional status on dose response}

After $12 \mathrm{~h}$ incubation with phytoplankton, the guts of larvae contained red-pigmented cells of Rhodomonas sp. and yellow-green cells of Isochrysis galbana and Pavlova lutheri, which were digested over time. This is the first observation of feeding by 'lecithotrophic' larvae of Alderia sp. We therefore tested whether feeding allowed larvae to maintain a higher threshold dose for the habitat cue, by sustaining their energy reserves and hence offsetting the effects of age. As before, unfed larvae responded more strongly to a range of doses after 3 and $5 \mathrm{~d}$; in contrast, fed larvae did not become more responsive with age (Fig. 3). A multiple

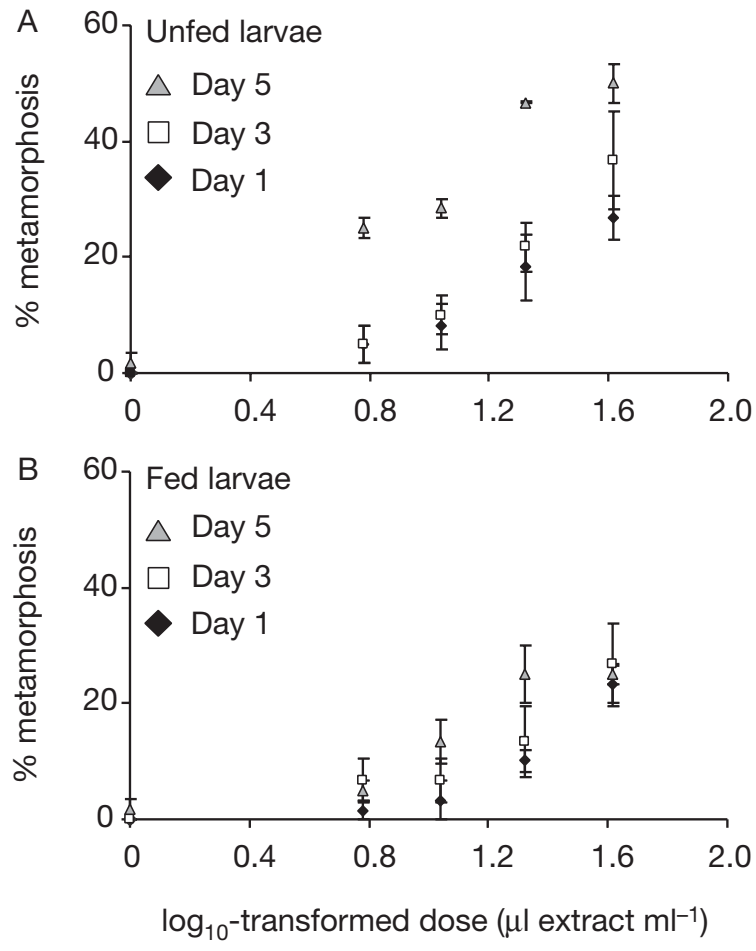

Fig. 3. Alderia sp. Effects of age and feeding on dose response of larvae. Data are mean $( \pm 1 \mathrm{SE})$ percentages of metamorphosis for larvae tested 1, 3 and 5 d post-hatching. (A) Dose response of unfed larvae hatched and maintained in filtered seawater; (B) dose response of larvae incubated with phytoplankton at $\sim 10^{4}$ cells $\mathrm{ml}^{-1}$ immediately upon hatching and for the duration of the experiment 
Table 3. Alderia sp. Results of multiple linear regression for effects of log-transformed dose of boiled Vaucheria longicaulis extract (BVE), larval age, and fed versus unfed status on percent metamorphosis

\begin{tabular}{|c|c|c|c|c|c|}
\hline \multicolumn{6}{|c|}{ Multiple linear regression model } \\
\hline Variable & Coefficient & \multicolumn{2}{|l|}{$\mathrm{SE}$} & $t$-value & $\mathrm{p}$ \\
\hline Intercept & -0.109 & \multicolumn{2}{|l|}{0.038} & -2.86 & 0.005 \\
\hline $\log ($ dose $)$ & 0.35 & \multicolumn{2}{|l|}{0.024} & 14.67 & $<0.0001$ \\
\hline Age & 0.05 & \multicolumn{2}{|l|}{0.008} & 6.23 & $<0.0001$ \\
\hline Fed/unfed & -0.117 & \multicolumn{2}{|l|}{0.026} & -4.44 & $<0.0001$ \\
\hline \multicolumn{2}{|c|}{ RMS residual $=0.144$} & \multicolumn{2}{|c|}{$\mathrm{R}^{2}=0.702$} & \multicolumn{2}{|c|}{ adjusted $R^{2}=0.695$} \\
\hline \multicolumn{6}{|c|}{ Analysis of variance } \\
\hline Source of $v$ & riation df & SS & MS & $F_{\mathrm{s}}$ & $\mathrm{p}$ \\
\hline Regression & 3 & 5.68 & 1.90 & 91.19 & 0.0001 \\
\hline Error & 116 & 2.41 & 0.02 & & \\
\hline Total & 119 & 8.09 & & & \\
\hline
\end{tabular}

linear regression yielded a significant model (Table 3 ; $F_{3,116}=91.19, \mathrm{p}<0.0001$, adjusted $\left.R^{2}=0.695\right)$. The negative regression coefficient for fed versus unfed status indicates that fed larvae metamorphosed less than unfed larvae. By feeding, larvae maintained a higher threshold of response for the soluble settlement cue, counteracting the effects of age, which otherwise lowered the response threshold as larvae became nutritionally deprived.

\section{Effects of prior exposure to a subthreshold dose on subsequent response}

Prior exposure to a subthreshold dose of the algal cue significantly affected the likelihood of subsequent larval metamorphosis, either in FSW or upon restimulation at the same concentration (Fig. 4). A 2-way ANOVA revealed significant effects of treatment and batch on response, but no interaction, and both batches showed the same pattern (Table 4). The highest percentage of metamorphosis was induced in Treatment A (dose-dose), when initial non-responders were re-exposed to the cue (Fig. 4, and results of a post-hoc Scheffé test, $p<0.005)$. In Treatment B (dose-FSW), more initial non-responders metamorphosed during the second $2 \mathrm{~d}$ interval in FSW than in unexposed controls (Fig. 4, and results of a post-hoc Scheffé test, $\mathrm{p}<0.005)$. The eventual percent metamorphosis among initial non-responders was significantly higher than that of initial responders in Treatment B (paired Student's $t$-test: $t=2.9, \mathrm{p}=0.023$ ). In Treatment C (FSW-dose), larvae initially kept in FSW were exposed to a low dose of cue at $3 \mathrm{~d}$ of age, inducing levels of metamorphosis higher than in unexposed controls (Fig. 4, and results of a post-hoc Scheffé test,

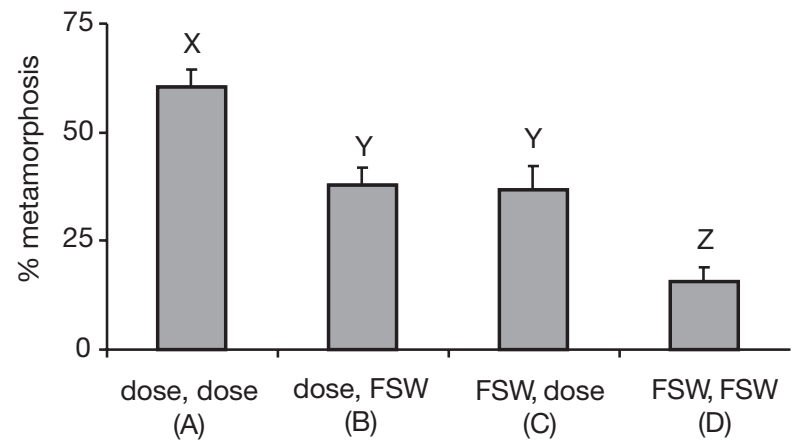

Fig. 4. Alderia sp. Effects of prior exposure to subthreshold dose of algal cue on subsequent metamorphosis of larvae. For the first $2 \mathrm{~d}$ post-hatching, larvae $(\mathrm{n}=4$ replicate dishes per treatment) were exposed to $0.2 \%$ boiled Vaucheria longicaulis extract (BVE, Treatments A and B) or filtered seawater (FSW, Treatments C and D). Larvae that did not metamorphose in this initial treatment were washed in FSW for $1 \mathrm{~d}$, after which remaining veligers were incubated in $0.2 \%$ BVE (Treatments A and C) or FSW (Treatments B and D) for a further $2 \mathrm{~d}$. Data are mean $(+1 \mathrm{SE})$ percentages of metamorphosis among larvae at the end of the second exposure (on the 5th day post-hatching). Means marked with same letter did not differ significantly (post-hoc Scheffé test, $\mathrm{p}>0.05)$. Data are pooled results from 2 independent batches of larvae that showed the same trend

$\mathrm{p}<0.005$ ) but roughly equivalent to those in Treatment B. The magnitude of response to re-stimulation in Treatment A suggested an additive effect of the delayed response to the first dose (as in Treatment B) plus the effect of increased age on response (as in Treatment C).

\section{Effect of age on settlement behavior and rate of metamorphosis}

Unfed larvae were exposed to the host alga starting 1,2 , or $4 \mathrm{~d}$ after hatching. Regardless of age, $>75 \%$ of larvae settled after $2 \mathrm{~h}$ of exposure to live filaments of the host alga (Fig. 5). Both 1 and 2 d old larvae set-

Table 4. Alderia sp. Results of 2-way ANOVA comparing effects of (1) treatment, and (2) batch, on percent metamorphosis. Percentages were arcsine square root transformed prior to statistical analysis. Treatments are fully described in Table 1

\begin{tabular}{|lccccc|}
\hline Source of variation & df & SS & MS & \multicolumn{1}{c|}{$F_{\mathrm{s}}$} & $\mathrm{p}$ \\
\hline Treatment & 3 & 1.08 & 0.36 & 20.02 & $<0.0001$ \\
Batch & 1 & 0.15 & 0.15 & 8.25 & 0.005 \\
Treatment $\times$ batch & 3 & 0.04 & 0.01 & 0.77 & 0.52 \\
Residual & 24 & 0.43 & 0.02 & & \\
Total & 59 & 1.70 & & & \\
\hline
\end{tabular}


tled rapidly but delayed metamorphosis (Fig. 5A,B). Neither $1 \mathrm{~d}$ nor $2 \mathrm{~d}$ old larvae metamorphosed in the first $12 \mathrm{~h}$, and significantly fewer had metamorphosed after $24 \mathrm{~h}$ than after $48 \mathrm{~h}$ (Wilcoxon signed-rank test: $1 \mathrm{~d}$ old larvae, $Z=2.8, \mathrm{p}<0.005 ; 2 \mathrm{~d}$ old larvae, $Z=$ $2.2, \mathrm{p}<0.05)$. In contrast, about a third of $4 \mathrm{~d}$ old larvae metamorphosed within $12 \mathrm{~h}$, and nearly all completed metamorphosis within $24 \mathrm{~h}$ (Fig. 5C). Older, unfed larvae thus initiated or completed metamorphosis more rapidly after settlement. Young larvae settled quickly, but either delayed the onset of metamorphosis for 12 to $24 \mathrm{~h}$, or completed the developmental transformation more slowly than older larvae.
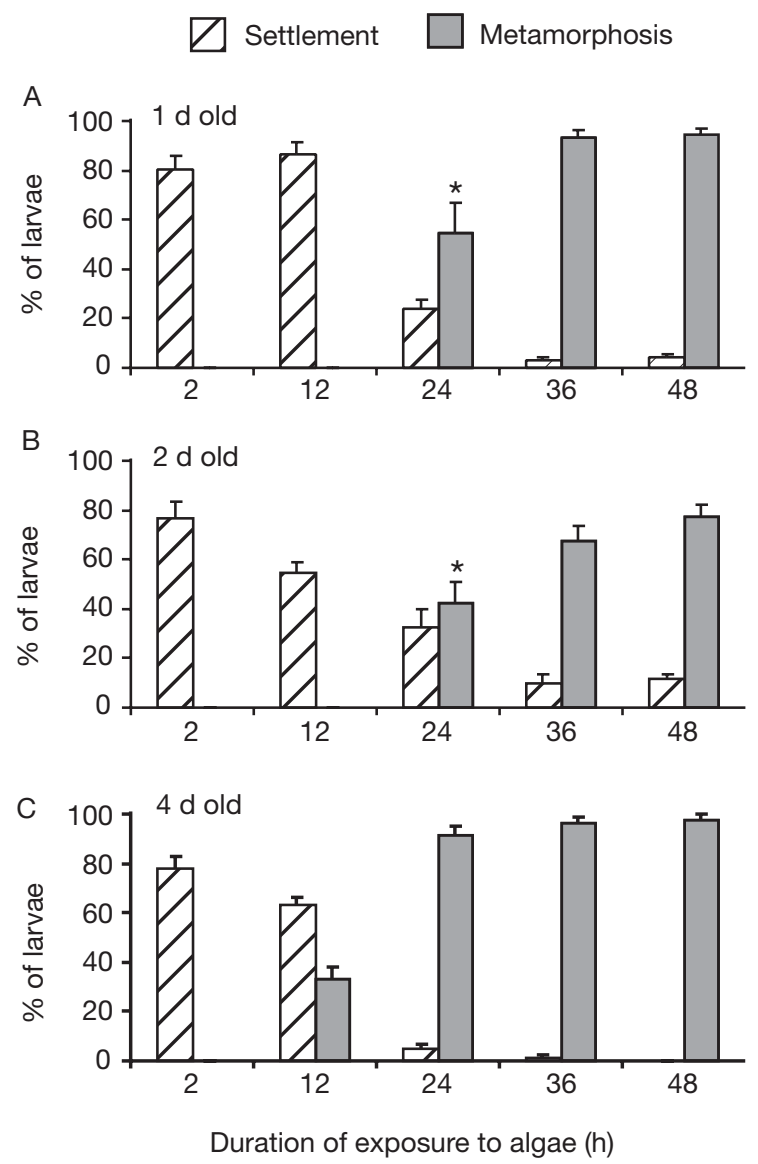

Fig. 5. Alderia sp. Effects of age on settlement and rate of metamorphosis of larvae. Settlement is firm but reversible attachment to a substrate, whereas metamorphosis is an irreversible transformation to a juvenile slug. Data are mean (+1 SE) percentages of larvae having settled or completed metamorphosis at the indicated interval during exposure to live filaments of Vaucheria longicaulis. Larvae were hatched and maintained in filtered seawater for (A) $1 \mathrm{~d}$, (B) $2 \mathrm{~d}$, or (C) $4 \mathrm{~d}$ prior to initial exposure to the host alga. Means labeled with asterisk were significantly lower after $24 \mathrm{~h}$ than the corresponding mean after $48 \mathrm{~h}$ for that age class (Wilcoxon signed-rank test); asterisk indicates $\mathrm{p}<0.05$

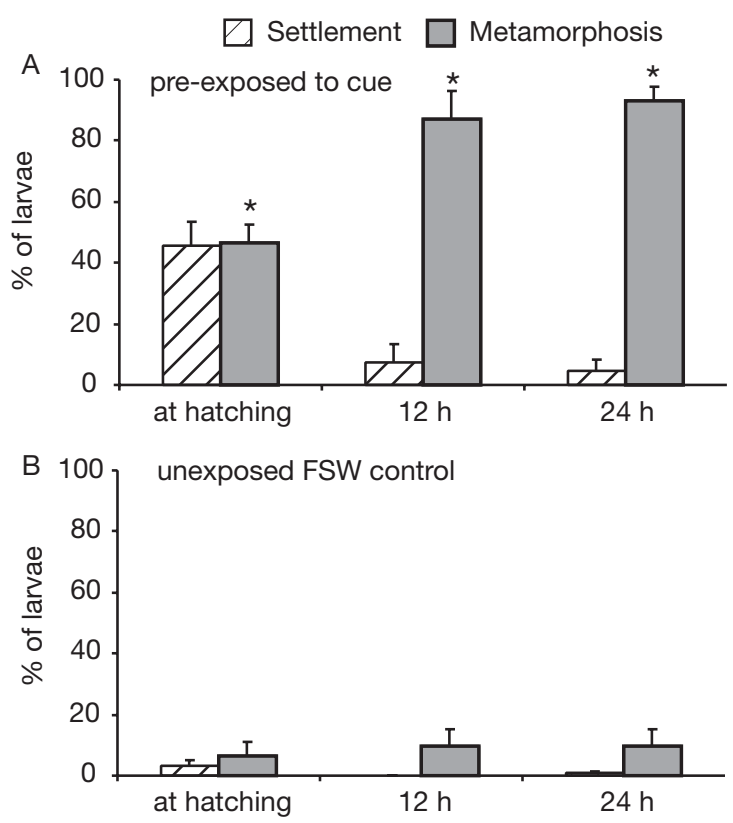

Fig. 6. Alderia sp. Competence of encapsulated veligers prior to hatching from egg masses. Data are mean (+1 SD) percentages of settlement (crawling behavior) and metamorphosis scored at hatching, and 12 and $24 \mathrm{~h}$ thereafter. (A) Response of veligers exposed to algal cues for last $2 \mathrm{~d}$ of encapsulation prior to hatching; (B) response of control veligers in egg masses maintained and hatched in filtered seawater (FSW). Means labeled with an asterisk in (A) were significantly different from controls of same age in (B) (Mann-Whitney $U$-test); asterisk indicates $\mathrm{p}<0.05$

\section{Assessment of competence prior to hatching}

To confirm that larvae were competent immediately upon hatching, encapsulated embryos were exposed to dissolved cues emanating from live algae for $2 \mathrm{~d}$ (Fig. 6). When control egg masses began hatching, $>90 \%$ of embryos pre-exposed to algal cues had settled or metamorphosed into juveniles. By $12 \mathrm{~h}$ posthatching, $87 \pm 9 \%$ of pre-exposed larvae had completed metamorphosis, significantly more than the $9 \pm$ $5 \%$ of larvae in FSW controls (Mann-Whitney $U$-test: $\mathrm{n}=8, Z=-2.31, \mathrm{p}=0.021$ ). Thus, attainment of competence was not a confounding factor in experiments with larvae of different ages, as embryos are competent to metamorphose prior to hatching as swimming veliger larvae.

\section{DISCUSSION}

The DHL is a 50 yr old postulate that older, energylimited larvae are more likely to settle on a suboptimal substrate than younger, energetically unconstrained larvae (Knight-Jones 1953b). Initially, 3 lines of evi- 
dence suggested that the DLH would not apply to Alderia sp. First, most spontaneous metamorphosis occurs in the first $2 \mathrm{~d}$ post-hatching (Krug 2001). This acts as a bet-hedging strategy, retaining some offspring in the natal habitat while the rest disperse until encountering the host alga. Second, $\sim 70 \%$ of programmed dispersers died over 2 wk without metamorphosing spontaneously when denied access to the host. Third, larvae did not become less discriminating with age over a $9 \mathrm{~d}$ period (Krug 2001). These results are contrary to the predictions of the original DLH, which holds that older larvae should metamorphose spontaneously or less specifically as they exhaust their energy reserves. However, in the absence of their obligate host, metamorphosis would be fatal for larvae of Alderia sp. that have dispersed from the parental environment.

The present results demonstrate that competent larvae of Alderia sp. become increasingly sensitive to habitat cues as they age. The effects of age are inhibited if larvae are allowed to feed, supporting the basic premise of the DLH that larvae are more likely to accept a suboptimal habitat as their energy reserves become depleted. The increased dose response of older larvae can be viewed as acceptance of inferior signals of habitat suitability, as levels of waterborne cues decrease with proximity to algal patches (Krug \& Zimmer 2000b).

We therefore propose a revised version of the DHL, applicable to larvae with specific settlement-cue requirements that reflect coevolution with an obligate host or prey species. Our revised DLH states that as energy reserves diminish over time, non-feeding larvae respond to lower concentrations of habitat cues, or initiate metamorphosis more rapidly upon stimulation by an inductive substrate. This reflects the core idea of the original DHL, while incorporating a constraint imposed by trophic specialization that does not affect filter-feeding organisms. As metamorphosis in the absence of an obligate food source is likely to be a fatal mistake regardless of remaining energy, larvae of specialist consumers such as Alderia sp. respond to lower doses or metamorphose more rapidly with age. Older larvae thus accept a potentially poor environment, but only in response to, at minimum, a weaker cue that the required host is present. More generalist consumers, such as the grazing cephalaspidean opisthobranch Haminoea calledigenita, show the expected pattern of increased metamorphosis on diverse substrata (Chaetomorpha spp., Zostera spp.) with age because juveniles do not depend on a single prey species (Gibson 1995).

Length of the prior dispersal period also affected how quickly larvae initiated metamorphosis after encountering the host. Settlement is a reversible attachment during which larvae may continue to evaluate their surroundings, eventually returning to the plankton or initiating metamorphosis. Younger lecithotrophic larvae ( 1 to $2 \mathrm{~d}$ old) delayed the onset of metamorphosis for $\sim 24 \mathrm{~h}$ after settlement, whereas most $4 \mathrm{~d}$ old larvae metamorphosed within 12 to $24 \mathrm{~h}$ of contact with Vaucheria longicaulis. Through rapid changes in swimming behavior (Krug \& Zimmer 2000a) and induction of settlement, larvae tend to remain at the initial touchdown site once a suitable adult habitat is encountered. For larvae that have survived a risky planktonic phase, rapid metamorphosis may be adaptive even when signals of viable habitat are weak, if it precludes further time in the plankton; this is consistent with the predictions of our revised DHL. A similar result was obtained with lecithotrophic larvae of the polychaete Spirorbis borealis: larvae aged $3 \mathrm{~h}$ settled at approximately twice the rate of freshly hatched larvae, in addition to exhibiting reduced gregariousness and substratum specificity (Knight-Jones 1953b). Non-feeding larvae of the polychaete Capitella sp. I also showed higher rates of metamorphosis when exposed to settlement-inducing mud at an advanced age (Pechenik \& Cerulli 1991).

As encapsulated larvae metamorphosed prior to hatching when exposed to Vaucheria longicaulis, the delayed response of 1 and $2 \mathrm{~d}$ old larvae was not due to any lag in attainment of competence. Rather, young lecithotrophic larvae have sufficient energetic reserves to last several more days, and can afford to be selective. Such larvae may continue to evaluate their environment after settlement, delaying the irreversible commitment to metamorphosis until cues of habitatsuitability have been continuously perceived for at least $12 \mathrm{~h}$. Older larvae that are in danger of exhausting endogenous reserves initiate metamorphosis (itself an energetically costly process) more rapidly after settlement. Post-settlement evaluation of habitat occurs in bivalve larvae, which can secondarily detach from the substrate and relocate to a preferred site (CaceresMartinez et al. 1994, Gilg \& Hilbish 2000, Erlandsson \& McQuaid 2004); however, this phenomenon has not been explored for larvae from other taxa, which may have different thresholds for initial settlement and eventual metamorphosis.

Larvae of the bryozoan Bugula neritina and the ascidians Diplosoma listerianum and Watersipora subtorquata showed size-dependent differences in settlement behavior, with larger larvae taking longer to settle and successfully attaching to preferred substrata (Marshall \& Keough 2003). In these taxa, size probably correlates with energy content, indicating that larvae with superior maternally endowed reserves are better able to make adaptive settlement choices (Marshall et al. 2003a, Marshall \& Keough 2004). Lecithotrophic larval stages of diverse taxa deplete both endogenous proteins and triacylglycerol during their planktonic 
period and metamorphosis (Satuito et al. 1996, Shilling et al. 1996, Hunter et al. 1998, Moran \& Manahan 2003). The ability of Alderia sp. to feed facultativelymay offset the energetic costs of a protracted larval period that are incurred by strictly non-feeding larvae of other species. Additional studies on specialist consumers like Alderia sp. with lecithotrophic larvae are needed to test the generality of our revised DHL.

Varying results have been obtained when the DHL is applied to obligately planktotrophic larvae of different species. Larvae of the opisthobranch Hermissenda crassicornis were more likely to undergo spontaneous metamorphosis with age (Avila 1998). Competent planktotrophic larvae of the polychaete Hydroides dianthus did not lose specificity for the adultassociated settlement cue with age if fed, and lost competency rather than specificity if starved (Pawlik \& Mense 1994, Toonen \& Pawlik 2001a). Recruitment to biofilmed substrata reflects a stable settlement-cue dimorphism in $H$. dianthus rather than a 'desperate' choice, as founder larvae are genetically programmed to settle in the absence of conspecific adults (Toonen \& Pawlik 1994, 2001b). In contrast, competent planktotrophic larvae of the filter-feeding gastropod Crepidula fornicata were stimulated to metamorphose prematurely by food limitation (Pechenik et al. 1996). Nutritional deprivation and age may therefore affect obligately feeding larvae differently from those that feed facultatively or not at all.

The larger larval morph of Alderia sp. was previously termed lecithotrophic, as it need not consume particulate food to complete metamorphosis (Krug 1998). However, the strict definition of lecithotrophy used by some authorities requires that larvae be incapable of feeding (Chia 1974). In the present study, the larger larvae of Alderia sp. captured and digested phytoplankton when available; they are therefore facultatively planktotrophic. This could generate confusion, however, as obligately planktotrophic larvae of a much smaller hatching size are also produced by this species (Krug 1998). Further, it is unclear whether feeding is ecologically relevant to these larvae, which have a brief free-swimming period and are rare in plankton tows over Vaucheria longicaulis mats. We therefore suggest that the term 'lecithotrophic' be retained for describing the larger larvae, while noting whether they have been fed or reared without food in laboratory studies. The larger 'lecithotrophic' larvae of the poecilogonous spionid polychaete Streblospio benedicti are also facultatively planktotrophic, suggesting this may be a general phenomenon of taxa that stably express multiple development modes from a single genome (Pernet \& McArthur in press).

Our preliminary results suggest a genetic basis for sensitivity to habitat cues, indicating that parentage affects the degree of larval response to a given dose of algal extract and that this trait may respond to natural selection. Regular fluctuations in host algal abundance, phytoplankton levels, or abiotic conditions could maintain polymorphism in dose-response thresholds and development modes in Alderia sp. Poecilogony evolved in Alderia sp. but not in its strictly planktotrophic sibling species A. modesta, which occurs from Bodega Bay northward; conditions in central and southern California apparently favor reduced dispersal, at a cost of lower fecundity (R. A. Ellingson \& P. J. Krug unpubl. data). At least 3 mechanisms exist in Alderia sp. to reduce the dispersal potential of some offspring. First, slugs switch seasonally between planktotrophy and lecithotrophy in the field, in response to changing environmental conditions (P. J. Krug unpubl. data). This reduces the dispersal period from weeks (planktotrophy) to hours or days (lecithotrophy). Second, in most clutches a variable percentage of lecithotrophic larvae spontaneously metamorphose within 1 to $2 \mathrm{~d}$ of hatching, further decreasing dispersal for a subset of offspring (Krug 2001). Third, as dissolved cues from Vaucheria longicaulis can permeate egg masses, high levels of pre-hatching metamorphosis may result when clutches are deposited on algal mats saturated with inductive exudate (Krug \& Zimmer 2000b). Field and laboratory observations indicate that adult slugs either crawl off $V$. longicaulis to deposit clutches on bare sediment, which should promote dispersal, or else lay egg masses directly on the alga, which will inhibit dispersal. This may account for the extreme rarity of competent larvae of Alderia sp. in plankton samples drawn immediately above beds of $V$. longicaulis (D. A. Willette \& P. J. Krug unpubl. data).

Despite the influence of adult reproductive behavior on dispersal potential, habitat choice remains largely the province of individual larvae. In Alderia sp., larvae express complex swimming and settlement behaviors that vary with development mode and age (Krug \& Zimmer 2000a, 2004). The evaluations made by a larva reflect its genetic background, prior exposure to cues, current energy levels and the chemical signals in its surroundings. When integrated by the larval nervous system, these factors ultimately determine the acceptance of a potential juvenile environment or the resumption of a risky planktonic existence.

Acknowledgements. This study was supported by awards from the National Science Foundation (OCE 02-42272 and HRD 03-17772). Access to field sites was provided by I. Kay through the Natural Reserve Office of the University of California (San Diego), B. Shelton (Newport) and M. Schaadt (San Pedro). We thank D. Willette, N. Smolensky and S. de la Calle for assistance with field collections or laboratory work, and $\mathrm{M}$. Donahue and R. Gould for assistance with statistics. 


\section{LITERATURE CITED}

Angeloni L (2003) Sexual selection in a simultaneous hermaphrodite with hypodermic insemination: body size, allocation to sexual roles and paternity. Anim Behav 66: $417-426$

Avila C (1998) Competence and metamorphosis in the longterm planktotrophic larvae of the nudibranch mollusc Hermissenda crassicornis (Escholtz, 1831). J Exp Mar Biol Ecol 231:81-117

Caceres-Martinez J, Robledo JAF, Figueras A (1994) Settlement and post-larvae behavior of Mytilus galloprovincialis - field and laboratory experiments. Mar Ecol Prog Ser 112:107-117

Chia FS (1974) Classification and adaptive significance of developmental patterns in marine invertebrates. Thalassia Jugosl 10:121-130

Erlandsson J, McQuaid CD (2004) Spatial structure of recruitment in the mussel Perna perna at local scales: effects of adults, algae and recruit size. Mar Ecol Prog Ser 267: 173-185

Gibson G (1995) Why be choosy? Temporal changes in larval sensitivity to several naturally occurring metamorphic inducers in the opisthobranch Haminaea callidegenita. J Exp Mar Biol Ecol 194:9-24

Gilg MR, Hilbish TJ (2000) The relationship between allele frequency and tidal height in a mussel hybrid zone: a test of the differential settlement hypothesis. Mar Biol 137: $371-378$

Hunter E, Okano K, Tomono Y, Fusetani N (1998) Functional partitioning of energy reserves by larvae of the marine bryozoan Bugula neritina (L.). J Exp Biol 201:2857-2865

Hunter E, Shimizu K, Fusetani N (1999) Role of protein in larval swimming and metamorphosis of Bugula neritina (Bryozoa: Cheilostomida). Mar Biol 133:701-707

Jaeckle WB, Manahan DT (1989) Feeding by a 'nonfeeding' larva: uptake of dissolved amino acids from seawater by lecithotrophic larvae of the gastropod Haliotis rufescens. Mar Biol 103:87-94

Kempf SC, Hadfield MG (1985) Planktotrophy in the lecithotrophic larvae of a nudibranch, Phestilla sibogae (Gastropoda). Biol Bull 169:119-130

Kempf SC, Todd CD (1989) Feeding potential in the lecithotrophic larvae of Adalaria proxima and Tritonia hombergi: an evolutionary perspective. J Mar Biol Assoc UK 69:659-682

Knight-Jones EW (1951) Gregariousness and some other aspects of the settling behavior of Spirorbis. J Mar Biol Assoc UK 30:201-222

Knight-Jones EW (1953a) Laboratory experiments on gregariousness during settling in Balanus balanoides and other barnacles. J Exp Biol 30:584-599

Knight-Jones EW (1953b) Decreased discrimination during settling after a prolonged planktonic life in larvae of Spirorbis borealis (Serpulidae). J Mar Biol Assoc UK 32: 337-345

Knight-Jones EW, Stevenson JP (1950) Gregariousness during settlement in the barnacle Elminius modestus Darwin. J Mar Biol Assoc UK 29:281-297

Krug PJ (1998) Poecilogony in an estuarine opisthobranch: planktotrophy, lecithotrophy, and mixed clutches in a population of the ascoglossan Alderia modesta. Mar Biol 132: 483-494

Krug PJ (2001) Bet-hedging dispersal strategy of a specialist marine herbivore: a settlement dimorphism among sibling larvae of Alderia modesta. Mar Ecol Prog Ser 213:177-192

Krug PJ, Manzi AE (1999) Waterborne and surface-associated carbohydrates as settlement cues for larvae of the specialist marine herbivore Alderia modesta. Biol Bull 197:94-103

Krug PJ, Zimmer RK (2000a) Developmental dimorphism and expression of chemosensory-mediated behavior: habitat selection by a specialist marine herbivore. J Exp Biol 203: 1741-1754

Krug PJ, Zimmer RK (2000b) Larval settlement: chemical markers for tracing production, transport, and distribution of a waterborne cue. Mar Ecol Prog Ser 207:283-296

Krug PJ, Zimmer RK (2004) Developmental dimorphism: consequences for habitat selection and dispersal potential in a marine gastropod. Biol Bull 207:233-246

Maldonado M, Young CM (1999) Effects of the duration of larval life on postlarval stages of the demosponge Sigmadocia caerulea. J Exp Mar Biol Ecol 232:9-21

Marshall DJ, Keough MJ (2003) Variation in the dispersal potential of non-feeding invertebrate larvae: the desperate-larva hypothesis and larval size. Mar Ecol Prog Ser 255:145-153

Marshall DJ, Keough MJ (2004) When the going gets rough: effect of maternal size manipulation on larval quality. Mar Ecol Prog Ser 272:301-305

Marshall DJ, Bolton TF, Keough MJ (2003a) Offspring size affects the post-metamorphic performance of a colonial marine invertebrate. Ecology 84:3131-3137

Marshall DJ, Pechenik JA, Keough MJ (2003b) Larval activity levels and delayed metamorphosis affect post-larval performance in the colonial ascidian Diplosoma listerianum. Mar Ecol Prog Ser 246:153-162

Miller SE (1993) Larval period and its influence on post-larval life history: comparison of lecithotrophy and facultative planktotrophy in the aeolid nudibranch Phestilla sibogae. Mar Biol 117:635-645

Moran AL, Manahan DT (2003) Energy metabolism during larval development of green and white abalone, Haliotis fulgens and H. sorensoni. Biol Bull 204:270-277

Pawlik JR (1992) Chemical ecology of the settlement of benthic marine invertebrates. Annu Rev Oceanogr Mar Biol 30:273-335

Pawlik JR, Mense DJ (1994) Larval transport, food limitation, ontogenetic plasticity, and the recruitment of sabellariid polychaetes. In: Wilson WH, Stricker SA, Shinn GL (eds) Reproduction and development of marine invertebrates. Johns Hopkins University Press, Friday Harbor, WA, p 275-286

Pechenik JA (1990) Delayed metamorphosis by larvae of benthic marine invertebrates: Does it occur? Is there a price to pay? Ophelia 32:63-94

Pechenik JA (1999) On the advantages and disadvantages of larval stages in benthic marine invertebrate life cycles. Mar Ecol Prog Ser 177:269-297

Pechenik JA, Cerulli TR (1991) Influence of delayed metamorphosis on survival, growth, and reproduction of the marine polychaete Capitella sp. I. J Exp Mar Biol Ecol 151: $17-27$

Pechenik JA, Estrella MS, Hammer K (1996) Food limitation stimulates metamorphosis of competent larvae and alters postmetamorphic growth rate in the marine prosobranch gastropod Crepidula fornicata. Mar Biol 127:267-275

Pechenik JA, Jarrett JN, Rooney J (2002) Relationships between larval nutritional experience, larval growth rates, juvenile growth rates, and juvenile feeding rates in the prosobranch gastropod Crepidula fornicata. J Exp Mar Biol Ecol 280:63-78

Pernet B, McArthur L (in press) Feeding by larvae of two different developmental modes in the annelid Streblospio benedicti (Polychaeta: Spionidae). Mar Biol 
Qian PY, Pechenik JA (1998) Effects of larval starvation and delayed metamorphosis on juvenile survival and growth of the tube-dwelling polychaete Hydroides elegans (Haswell). J Exp Mar Biol Ecol 227:169-185

Satuito CG, Shimizu K, Natoyama K, Yamazaki M, Fusetani N (1996) Age-related settlement success by cyprids of the barnacle Balanus amphitrite, with special reference to consumption of cyprid storage protein. Mar Biol 127: 125-130

Shilling FM, Hoegh-Guldberg O, Manahan DT (1996) Sources of energy for increased metabolic demand during metamorphosis of the abalone Haliotis rufescens (Mollusca). Biol Bull 191:402-412

Sokal RR, Rohlf FJ (1995) Biometry. The principles and practice of statistics in biological research, 3rd edn. WH Freeman, New York

Tamburri MN, Zimmerfaust RK, Tamplin ML (1992) Natural sources and properties of chemical inducers mediating

Editorial responsibility: Joseph Pawlik (Contributing Editor), Wilmington, North Carolina, USA settlement of oyster larvae - a reexamination. Biol Bull 183:327-338

Toonen RJ, Pawlik JR (1994) Foundations of gregariousness. Nature 370:511-512

Toonen RJ, Pawlik JR (2001a) Settlement of the gregarious tube worm Hydroides dianthus (Polychaeta:Serpulidae). II. Testing the desperate-larva hypothesis. Mar Ecol Prog Ser 224:115-131

Toonen RJ, Pawlik JR (2001b) Foundations of gregariousness: a dispersal polymorphism among the planktonic larvae of a marine invertebrate. Evolution 55:2439-2454

Wendt DE (1998) Effect of larval swimming duration on growth and reproduction of Bugula neritina (Bryozoa) under field conditions. Biol Bull 195:126-135

Woollacott RM, Pechenik JA, Imbalzano KM (1989) Effects of duration of larval swimming period on early colony development in Bugula stolonifera (Bryozoa: Cheilostomata). Mar Biol 102:57-63

Submitted: June 8, 2005; Accepted: September 26, 2005 Proofs received from author(s): March 27, 2006 